\title{
Patients report that root canal work isn't so bad
}

A study conducted in Australia suggests that root canal work is 'not so bad after all' when compared to other dental procedures. ${ }^{1}$

Information about 1,096 randomly selected Australian people aged 30-61 was collected through questionnaires, dental records and treatment receipts in 2009. Their self-rated dental health score was checked when they had their dental work and two years later.

Dr Tallan Chew, a postgraduate student at Adelaide Dental School who co-authored the study, said: 'Patients who had root canal work reported similar oral health-related quality of life as people who had other types of dental work. The effect of root canal work 产 on patients' oral health-related quality of 兽 life was compared to other kinds of dental wivestork such as tooth extraction, restoration of 善 teeth, repairs to the teeth or gum treatment, preventative treatment and cleaning.'

Every year millions of root canal treat๑) ments are performed globally (more than

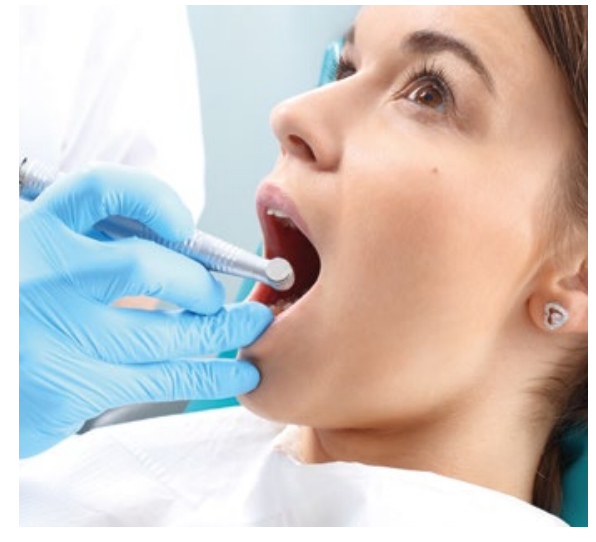

22 million in the USA alone). Most people associate having root canal work with a lot of pain and discomfort.

Fellow co-author Professor Giampiero

Rossi-Fedele, Head of Endodontics at Adelaide Dental School, said: 'There is growing interest in the dental profession to better understand the effect and impact oral diseases and their associated treatment, such as root canal work, have on patients' quality of life.
'Treatment outcomes need to be re-examined from a patient-based perspective using self-reported measures as this more accurately reflects the patients' perception of treatment outcomes and the effect it has on their overall well-being.

'Patient-reported treatment outcomes are now the principal driving force behind treatment needs, as opposed to clinician-based treatment outcomes.

'With this change in emphasis, the perspectives of patients and their relatives are important factors in identifying need for treatment, treatment planning, and determining outcomes from any healthcare intervention as part of shared decision making.'

\section{References}

1. Chew T, Brennan D, Rossi-Fedele G. Comparative longitudinal study on the impact root canal treatment and other dental services have on oral health-related quality of life using self-reported health measures (Oral Health Impact Profile-14 and Global Health Measures). J Endod 2019; 45: 985-993.e1.

\section{Here has been an advertisement.}

